7 - ORIGINAL ARTICLE

EXPERIMENTAL ONCOLOGY

\title{
Sulfane sulfur deficiency in malignant cells, increasing the inhibiting action of acetone cyanohydrin in tumor growth ${ }^{1}$
}

\author{
Rondon Tosta Ramalho', Ricardo Dutra Aydos ${ }^{\mathrm{II}}$, Iandara Schettert ${ }^{\mathrm{III}}$, Peterson Vieira de Assis ${ }^{\mathrm{IV}}$, Pedro Carvalho Cassino ${ }^{\mathrm{V}}$ \\ IMaster, Fellow PhD degree, Health and Development Postgraduate Program, Federal University of Mato Grosso do Sul (UFMS), Campo Grande-MS, \\ Brazil. Conception and design of the study, acquisition and interpretation of data, manuscript preparation. \\ IIPhD, Associate Professor, Department of Surgery, UFMS, Campo Grande-MS, Brazil. Guidance and experimental design of the study. \\ IIIPhD, Associate Professor, Department of Surgery, UFMS, Campo Grande-MS, Brazil. Veterinary assistance in the experimental study. \\ ${ }^{\text {IV }}$ Master, Health and Development Postgraduate Program, UFMS, Campo Grande-MS, Brazil. Interpretation of data, critical revision. \\ ${ }^{v}$ Fellow Master degree, Health and Development Postgraduate Program, UFMS, Campo Grande-MS, Brazil. Acquisition and statistical analysis of
} data.

\begin{abstract}
PURPOSE: To demonstrate the irreversible poisoning action of the acetone cyanohydrin (AC) in malignant cells.

METHODS: Thirty male Swiss mice were inoculated with $1 \times 10^{3}$ Ehrlich tumor (ET) cells. The mice were divided into three groups $(\mathrm{n}=10)$ : CG (saline); ACG1 (1.864 mg/Kg of AC) and ACG2 (2.796 mg/Kg of AC), treated every 48 hours from day 3 until day 13. On day 15 the mice were euthanized and the number of viable cells in ascites was determined. In the meantime, ET cells were incubated with $\mathrm{AC}(0.5,1.0,2.0 \mu \mathrm{g} / \mathrm{mL})$. Cell viability and percentage of growth inhibition (PGI) were checked after one, two, three, four, 18 and 24 hours.

RESULTS: There was reduction in volume and number of viable cells in ACG1 and ACG2 compared to CG. In ACG1 one of the animals did not present ascites. In ACG2 two mice did not present ascites and in CG none of the mice present ascites. The action of AC was dose and time dependent and there was no significant difference among the three doses.

CONCLUSION: The acetone cyanohydrin promoted reduction of the tumor and also prevented tumor development in $20 \%$ of the treated animals.
\end{abstract}

Key words: Antineoplastic Agents. Sulfur Compounds. Thiosulfate Sulfurtransferase. Mice. 


\section{Introduction}

Cancer study is being conducted by numerous scientists around the world and their findings in oncology make it one of the greatest and most rapidly evolving areas in modern medicine, causing great technological advances and a growing understanding of what cancer is.

Although cancer has many heterogeneous characteristics, malignant tumors have developed a feature which causes them to grow beyond the imposed limits of the regular cells. The clonal expansion of a transformed cell depends on its uncontrolled proliferative capacity and an increasing inability to die by apoptosis. Therefore, even though there is a great variety of cancer types, evidence has shown that resistance to apoptosis is one of the most remarking characteristics of the majority of malignant tumors ${ }^{1}$.

A feature of neoplastic cells is a complete lack of Cystationase (CST) activity, while cysteine aminotransferase, 3-mercaptopyruvate sulfurtransferase (MpST) e rhodanese activity is only residual. As a result, the biosynthesis and transport of compounds from the sulfane sulfur set do not occur in these cells. Toohey suggests that the uncontrolled proliferation of neoplastic cells is a result of the deficiency of sulfane sulfur and hyperactivity of these enzimes, which would be inhibited in regular cells by that active form of sulfur ${ }^{2,3}$.

The term sulfane sulfur refers to the set of compounds that contain one sulfur atom covalently bonded to another reduced sulfur atom. Proteins associated to sulfur, bonded sulfur and refer to specific compounds with sulfane sulfur. Thus, sulfane sulfur should not be used to relate to any of the terms mentioned above $\mathrm{e}^{3,4}$.

Sulfane Sulfur is generated from various metabolic pathways already described, and it is common to find carrier proteins with the ability to stabilize and transport it. Compounds that contain sulfane sulfur are able to regulate the activity of several enzymes and also have antioxidant properties. This deficiency in the anaerobic metabolism of sulfur is related to neoplastic processes, viral infections and immunodeficiency, suggesting that the sulfane sulfur may exert a regulatory function in cells by modifying the - $\mathrm{SH}$ groups and this high activity and short half-life characteristics make it an efficient regulator ${ }^{4}$.

Currently, there are some reviews in the literature carrying information such as characteristics of the sulfane compounds and its affinity to react with cyanide, evidence of metabolism in the malignancy processes, cystathionase deficiency in many malignant cells, and differences in homocysteine metabolism between normal and malignant cells ${ }^{3}$. It was also possible to gather important information regarding the defective sulfur metabolism in cancer cells with antitumor effects in sources of sulfane sulfur. This fact seems to show that the uncontrollable proliferation of malignant cells may be related to sulfane sulfur deficiency and to an uncontrollable action of the enzyme set, which is normally inactivated by such substance. Tumors with inherently high growth rates may have lower sulfur-transferase activities (rhodanese, for example) than the normal tissue and tumors with low growth rates $^{3,5,6}$.

The action of acetone cyanohydrin is based on its cyanide metabolite that comes from its spontaneous degradation in slightly alkaline $\mathrm{pH}$, which acts in lethal malignant cells taking advantage of a flaw in the cyanide metabolism in these cells, due to a suppressed action of the rhodanese enzyme, responsible for their detoxification. This residual action of the rhodanese enzyme would be triggered by a lack of substrate for the reaction, known as sulfane-sulfur, responsible for providing sulfur for disposal of cyanide as thiocyanate?

The advances in various fields of knowledge have led to increased insights about cancer biology, offering by far more means to fight the disease, its prevention, early diagnosis and new forms to treat it. However, it is known that there is still much to learn. Based on that, the present study seeks to highlight the action of cyanide from acetone cyanohidrin in alkaline $\mathrm{pH}$, exploring the sulfane sulfur deficiency in malignant cells, which promotes on them irreversible poisoning.

\section{Methods}

The research project was approved by the Ethics Committee in animal use of the Federal University of Mato Grosso do Sul (UFMS), under protocol number 227/2009.

A total of 30 male Swiss mice weighing an average of $35 \mathrm{~g}$ from the animal colony of the Federal University of Mato Grosso do Sul were used in this study. The animals were kept in the experiment for seven days prior the procedures. Randomly, the animals were divided into three groups: Control (CG), $n=10$, saline treated; Acetone cianohydrin 1 (ACG1), $n=10$, treated with $1.864 \mathrm{mg} / \mathrm{Kg}$ of Acetone cianohydrin; and Acetone cianohydrin 2 (ACG 2), n=10, treated with $2.796 \mathrm{mg} / \mathrm{Kg}$ of Acetone cianohydrin.

\section{$\underline{\text { Tumor transplant }}$}

The cells were kept in mice by the intraperitoneal transplantation of $2 \times 10^{6}$ EAT cells. Every ten days the formed intraperitoneal fluid was removed and transplanted in another 
animal.

Donor animals were euthanazied with an overdose of anesthetic. After that a peritoneal wash was performed with $3 \mathrm{~mL}$ of saline, and then performed again the same $3 \mathrm{~mL}$ withdrawal by suction. The obtained cell suspension was centrifuged, the supernatant discarded and the pellet resuspended in $3 \mathrm{ml}$ of saline. In the suspension, cell viability test was performed through the Trypan blue exclusion. Next, it was determined the number of cells in Newbauer chamber.

All three groups of mice received injections containing $0.4 \mathrm{ml}$ of cell suspension of Ehrlich ascites tumor (containing 1.0 $\mathrm{x} 10^{3}$ viable cells) in the peritoneal cavity

\section{$\underline{\text { Treatment program }}$}

The day of tumor inoculation in the animals was regarded as day 0 . Treatment was initiated on day 3 and repeated every 48 hours until day 13 . The $\mathrm{CG}$ received $0.4 \mathrm{ml}$ of saline intraperitoneally; ACG1 received $0.4 \mathrm{ml}$ of acetone cyanohydrin $1.864 \mathrm{mg} / \mathrm{kg}$ intraperitoneally and, the ACG2 received $0.4 \mathrm{ml}$ of acetone cyanohydrin $2.796 \mathrm{mg} / \mathrm{kg}$ intraperitoneally. 48 hours after the last treatment, the animals were euthanized by an overdose of anesthetic to measure the antitumor activity of acetone cyanohydrin.

\section{EAT cell viability}

EAT cell viability was checked Trypan blue test. The cells were stained with Trypan blue ( $0.4 \%$ in normal saline); those that did not incorporate the dye were considered viable, while others were unfeasible. These viable and non-viable cells were counted.

\section{In vitro experimental design}

\section{$\underline{\text { Cell preparation and culture }}$}

The EAT cells suspension obtained was washed two times and resuspended in Dulbecco's Modified Eagle's (DMEM) supplemented with $5 \%$ fetal bovine serum and the suspension adjusted to $1.0 \times 10^{5}$ cells $/ \mathrm{mL}$. After adjusting the concentration of $1.0 \times 10^{5}$ EAT cells the suspensions were separated into aliquots of $1.0 \mathrm{~mL}$ and cultured with 0 (control), $0.5,1.0$ and $2.0 \mu \mathrm{g}$ of acetone cyanohydrin in DMEM supplemented with 5\% fetal serum, with a pH between 7.0 and 7.2. After one, two, three, four, 18 and 24 hours cell viability tests were performed and the percentage of growth inhibition (PGI) was determined, and this procedure was repeated twice in duplicate.

To check significant differences among groups, the results were analyzed with one-way ANOVA followed by Tukey's multiple comparison test. The significance level was 5\% $(\mathrm{p}<0.05)$.

\section{Results}

In vitro experiment

The AC intraperitoneal administration at dose of 1,864 and $2,796 \mathrm{mg} / \mathrm{kg}$ body weight led to a reduction in tumor volume and viable cell count of tumor-bearing mice compared to control mice EAT (Table 1).

TABLE 1 - Effect of Acetone cyanohydrin in volume and count of viable tumor cells in mice with EAT.

\begin{tabular}{ccc}
\hline & $\begin{array}{c}\text { Total cells } \\
\left(\mathbf{1 0}^{\mathbf{7}}\right)\end{array}$ & $\begin{array}{c}\text { Volume } \\
(\mathbf{m L})\end{array}$ \\
\hline CG & $56.15 \pm 21.5$ & $8.6 \pm 2.24$ \\
\hline ACG1 & $24.42 \pm 12.51^{*}$ & $3.8 \pm 1.69 *$ \\
\hline ACG2 & $14.45 \pm 9.81^{*}$ & $3.12 \pm 1.79 *$ \\
\hline
\end{tabular}

Each value represents the average $\pm D P$. ( $n=10$ mice per group) $* \mathrm{p}<0.0001$, when treated and compared to the control group

In ACG1, only one animal showed no ascites at the end of 15 days, not presenting tumor cells after peritoneal wash with saline. In ACG2, two animals showed ascites and after the wash showed no peritoneal tumor cell counting. In the CG, all animals developed ascites and showed viable cells counting.

\section{In vitro experiment}

With the results shown in Figure 1, concerning the percentage of inhibition of EAT cell growth after treatment with $\mathrm{AC}$, it was found that doses of $\mathrm{AC}$ used showed the same pattern, where the inhibition was dose-and time-dependent. 
Sulfane sulfur deficiency in malignant cells, increasing the inhibiting action of acetone cyanohydrin in tumor growth

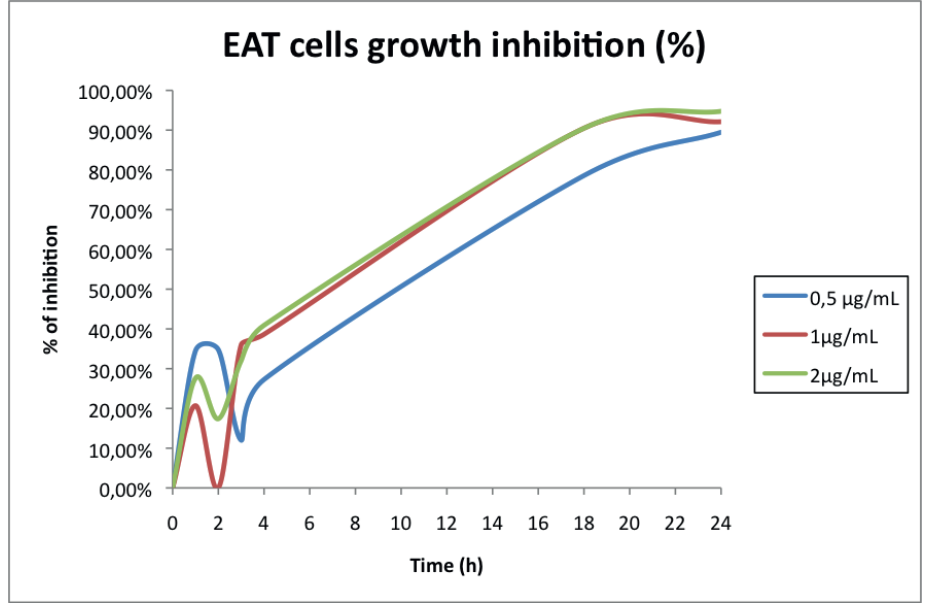

FIGURE 1 - inhibition growth curve after treatment with in vitro acetone cyanohydrin compared to control group.

The evaluation of the inhibition of the AC showed no significant difference between the three doses, 0.5, 1 and $2 \mathrm{mg} /$ $\mathrm{mL}, 24$ hours after reaching $89.47,92.11$ and $94.74 \%$ respectively.

\section{Discussion}

The use of Acetone cyanohydrin was motivated by the fact that its action in the organism is similar to its molar equivalent of cyanide. For example, the intraperitoneal lethal dose (LD50) in mice to Acetone cyanohydrin is equivalent to $2.65 \mathrm{mg}$ of cyanide ion $/ \mathrm{kg}$ which is similar to that of sodium cyanide which is 2.54 $\mathrm{mg} / \mathrm{kg}$ cyanide ion and has an average five minute-time to death for the two compounds. The LD50 of acetone cyanohydrin is 8.5 $\mathrm{mg} / \mathrm{kg}$ weigh ${ }^{8,9}$. In this experiment we used doses under the lethal values, 1.864 and $2.796 \mathrm{mg}$ of acetone cyanohydrin/Kg.

The tumor inhibition without causing acute poisoning in animals was only possible due to cyanide act promoting the inhibition of cytochrome $\mathrm{C}$ oxidase, an enzyme directly involved in mitochondrial respiration, thus promoting a decrease in ATP levels and resulting in cellular injury or establishing cell death, depending on its concentration ${ }^{8,10}$. However, due to unavoidable exposure to cyanide, living organisms have developed a selfdefense mechanism by conversion of cyanide to thiocyanate by the transfer of sulfur from the sulfane sulfur group (sulfur donors) for the cyanide by the rhodanese mitochondrial enzyme ${ }^{10,11}$. A feature present in cancer cells is the residual activity of rhodanese ${ }^{12}$, due to a deficiency of sulfane sulfur, which makes transport and biosynthesis of sulfur from sulfane not occur satisfactorily in such cells. This suggests that the uncontrolled proliferation of cancer cells is a result of deficiency of this compound, and that this active form of sulfur promotes inhibition of regular cell proliferation ${ }^{13,14}$
The sulfane sulfur is generated from multiple metabolic pathways and from protein which are capable of stabilize and transport it. The activity of a number of enzymes is regulated by compounds containing sulfane sulfur. It is believed that this substance can exert a regulatory activity through changes in $\mathrm{SH}$ groups, and disability in the anaerobic metabolism of sulfur is related to neoplastic processes and immunodeficiency virus infections, and such high activity and short half-life confer characteristics of an efficient regulator ${ }^{4}$. As a result, cells with sulfane sulfur deficiency have a significantly diminished rhodanese activity $^{2,6}$

The action of acetone cyanohydrin in both experiments, and, demonstrates the ability of tumor cells to irreversibly poison the action of cyanide, while normal cells are resistant to small doses of cyanide due to the protection afforded by mitochondrial rhodanese with its ability to detoxify cyanide to a certain extent. Once the limit is exceeded, however, the toxicity is expressed. The absence of this intracellular mechanism in tumor cells may explain their inability to eliminate cyanide efficiently. This provides a dose and time dependent effect ${ }^{15-17}$, as occurred in the experiment and previous study ${ }^{7}$. Cyanide toxicity occurs in two ways: ATP depletion caused by blockage of oxidative phosphorylation and production of reactive oxigen ${ }^{17}$.

The acetone cyanohydrin led to a significant decrease in tumor volume, leading to inhibition of the tumor in 3 animals, one from ACG1 and two from ACG2, which means that the higher dose in the cure rate was approximately $20 \%$. The literature also reports the success of therapy with cyanide using suicide gene, based on the transfer of an encoding B-glucosidase (linamarase) gene to tumor cells which, in the presence of an innocuous substrate (linamarin), produces cyanide, causing these cells to die proportionally to the concentration of linamarin ${ }^{17-20}$.

Evidence observed in the present study suggests that the selective action of cyanide is due to a deficiency in its elimination, which is observed in tumor cells as widely discussed in the literature. We believe that further studies are necessary before it is possible to fully understand the mechanism of action involved in the process.

\section{Conclusions}

Acetone cyanohydrin, through its molar equivalent of cyanide, was able to promote a reduction in tumor volume, a decrease in the total number of tumor cells, as well as prevent tumor development in $20 \%$ of the treated animals. In the experiment the acetone cyanohydrin presented a dose and time dependent action. 


\section{References}

1. Grivicich I, Regner A, da Rocha AB. Morte celular por apoptose. Rev Bras Cancerol. 2007;53(3):335-43.

2. Jurkowska H, Wróbel M. N-acetyl-L-cysteine as a source of sulfane sulfur in astrocytoma and astrocyte cultures: correlations with cell proliferation. Amino Acids. 2008;34:231-7.

3. Toohey JI. Sulphane sulphur in biological systems: a possible regulatory role. Biochem J. 1989;264:625-32.

4. Iciek M, Wlodek L. Biosynthesis and biological properties of compounds containing highly reactive, reduced sulfane sulfur. Pol J Pharmacol. 2001;53:215-25.

5. Jurkowska H, Placha W, Nagahara N, Wróbel M. The expression and activity of cystathionine-c-lyase and 3-mercaptopyruvate sulfurtransferase in human neoplastic cell lines. Amino Acids. 2011;41:151-8.

6. Jurkowska H, Wróbel M. N-acetyl-L-cysteine as a source of sulfane sulfur in astrocytoma and astrocyte cultures: correlations with cell proliferation. Amino Acids. 2008;34:231-7.

7. Ramalho RT, Aydos RD, Cereda MP. Evaluation of acetone cyanohydrin effect in "in vitro" inativation of the Ehrlich ascites tumor cells. Acta Cir Bras. 2010;25(1):111-6.

8. Magos L. A study of acrylonitrile poisoning in relation to methaemoglobin-cn complex formation. $\mathrm{Br} \mathrm{J}$ Industr Med. 1962;19:283-6.

9. Thompson RW, Valentine HL, Valentine WM. Cytotoxic mechanisms of hydrosulfide anion and cyanide anion in primary rat hepatocyte cultures. Toxicology. 2003;188:149-59.

10. Soto-Blanco B, Marioka PC, Gorniak SL. Effects of long-term low-dose cyanide administration to rats. Ecotoxicol Environ Saf. 2002;53:37-41.

11. Zottola MA. A partial exploration of the potential energy surfaces of SCN and HSCN: implications for the enzyme-mediated detoxification of cyanide. J Mol Graph Model. 2009;28:183-6.

12. Cibin TR, Gayathri Devi D, Abraham A. Chemoprevention of skin cancer by the flavonoid fraction of Saraca asoka. Phytother Res. 2010;24:666-72.

13. W'odek L, Wróbel M, Czubak J. Transamination and transsulphuration of L-cysteine in Ehrlich ascites tumor cells and mouse liver. The nonenzymatic reaction of L-cysteine with pyruvate. Int J Biochem. 1993;25:107-12.

14. Melino S, Sabelli R, Paci M. Allyl sulfur compounds and cellular detoxification system: effects and perspectives in cancer therapy. Amino Acids. 2011;41:103-12.

15. Yusuf UF, Ahmadun F, Rosli R, Iyuke SE, Billa N, Abdullah N, Umar-Tsafe N. An in vitro inhibition of human malignant cell growth of crude water extract of cassava (Manihot esculenta Crantz) and commercial linamarin. Songklanakarin J Sci Technol. 2006;28:145-55.

16. Chang H, Shin M, Yang H, Lee J, Kim Y, Lee M, Kim J, Kim K, Kim C. Amygdalin induces apoptosis through regulation of Bax and Bcl-2 expressions in human DU145 and LNCaP prostate cancer cells. Biol Pharm Bull. 2006;29:1597-602.

17. Kousparou CA, Epenetos AA, Deonarain MP. Antibody-guided enzyme therapy of cancer producing cyanide results in necrosis of targeted cells. Int J Cancer. 2002;99:138-48.

18. García-Escudero V, Gargini R, Izquierdo M. Glioma Regression In vitro and In vivo by a suicide combined treatment. Mol Cancer Res. 2008;6(3):407-17.

19. Cortés ML, García-Escudero V, Hughes M, Izquierdo M. Cyanide bystander effect of the linamarase/linamarin killer-suicide gene therapy system. J Gene Med. 2002;4:407-14.
20. Cortés ML, Felipe P, Martín V, Hughes MA, Izquierdo M. Successful use of a plant gene in the treatment of cancer in vivo. Gene Ther. 1998;5:1499-507.

\section{Acknowledgement}

To Profa. Isabella Saliba Pereira for revising the English language.

\section{Correspondence:}

Rondon Tosta Ramalho

Rua Talles, 178

79041-560 Campo Grande - MS Brasil

rondontosta@gmail.com

Received: June 12, 2013

Review: Aug 14, 2013

Accepted: Sept 12, 2013

Conflict of interest: none

Financial source: none

${ }^{1}$ Research performed at Laboratory of Experimental Carcinogenesis, Federal University of Mato Grosso do Sul (UFMS), Campo Grande-MS, Brazil. Part of PhD degree thesis, Health and Development Postgraduate Program. Tutor: Ricardo Dutra Aydos. 